Original article

\title{
Gender differential and regional disparity of disability-free life-expectancy among disable in India
}

\author{
Radhe Shyam Mishra ${ }^{\mathrm{a}}$, Raman Mishra ${ }^{\mathrm{a}, *}$, Sanjay K. Mohanty ${ }^{\mathrm{b}}$

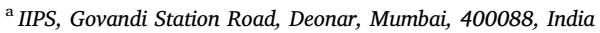 \\ ${ }^{\mathrm{b}}$ Department of Fertility Studies, IIPS, Govandi Station Road, Deonar, Mumbai, 400088, India
}

\section{A R T I C L E I N F O}

\section{Keywords:}

Type of disability

Disability-free life expectancy

Gender differential

And regional disparity

\begin{abstract}
A B S T R A C T
In the wake of demographic and epidemiological transition, rising life expectancy and disability has become a global, national and regional phenomenon. Though estimates of life expectancy at birth are available at regular time intervals, there are limited studies on estimates of disability-free life expectancy by gender and regions in India.

Study design: Compares life expectancy of disabled and overall population by seven type of disability.

Objective: This study examines the gender differential and regional disparity of disability-free life expectancy (DFLE) and Life lived with disability (LWD) among disabled in India.

Methods: Data from Census of India, 2011 and abridged life table from Sample Registration System 2011 has been used. Disability-free life expectancy (DFLE) was estimated using Sullivan method. Life lived with disability was calculated for all major states included in the study by the types of disabilities.

Results: In 2011, the DFLE in India was 58.1 years for males and 60.78 years for females compared to life expectancy of 66.87 years for males and 70 years for females. On average, females in India had lived more years with disability than males. Similarly, the DFLE of rural areas was 58.6 compared to 62.3 in urban areas. The DFLE was 59.26 years movement, 58.88 for mental retardation and 58.81 for mental illness. The age pattern of DFLE decreases with increasing age for both males and females. The regional variation in DFLE is large. The DFLE of males in the state of Jammu and Kashmir was 62.4 compared to 56.4 in Assam. Similarly, for females, the DFLE was 61.8 years in Gujarat and 63.1 years in Tamil Nadu.

Conclusion: Though the overall life expectancy and DFLE were higher for females than for males, females lived with disability for more years than males. The DFLE was lowest for mental retardation followed by mental illness. The poorer states of India has lower DFLE compared to richer states.
\end{abstract}

\section{Introduction}

Increasing life expectancy and disability is a world-wide phenomenon. While countries are conversing on life expectancy, they are diverging on the extent, nature and type of disability (WHO, 2001). About $15 \%$ of the world's population (nearly 150 million) have some form of disability $12 \%$ in higher-income countries and $18 \%$ in lower-income countries. $^{2}$ Increase in disability is associated with demographic and epidemiological transition. ${ }^{3}$ People with disabilities are more likely to live in poverty and social exclusion and have the higher health needs compared to non-disabled. ${ }^{4}$ Demographic transition has resulted in increasing life expectancy on the one hand, and on the other, increased the share of older population with a higher risk of disability. The epidemiologic transition has resulted in increases in the prevalence of non- communicable disease has higher chance of disability. ${ }^{5}$ Disability is an umbrella term, covering impairments, activity limitations and participation restrictions. ${ }^{4}$ Disability is not merely a health problem but a complex socioeconomic and cultural phenomenon. In addition to poor health and high morbidity, disabled people are more likely to be deprived in multiple domains, socially discriminated with a high incidence of poverty, poor education attainment and a low level of employment.

Disability has been increasingly recognized as a developmental issue among multiple stakeholders; academia, international organization, United Nations, national, state government and the civil society. ${ }^{6,7}$; Research demonstrated that socioeconomic disadvantage is strongly associated with disability. ${ }^{8}$ Limited health care facilities, lower coverage of social security system and little capacity to pay for health

\footnotetext{
* Corresponding author. International Institute for Population Sciences, Govandi Station Road, Deonar, Mumbai, 400088, India.

E-mail addresses: radheshyammishra111@gmail.com (R.S. Mishra), raman.mishra10@gmail.com (R. Mishra), sanjayiips@yahoo.co.in (S.K. Mohanty).
} 
services is the primary cause to increase disability among adults and elderly. The increase in disability is associated with demographic and epidemiological transition. The demographic transition is leading to increasing in the share of the older population which have a higher chance of disability. The epidemiologic transition framework was extended to include propositions regarding patterns of disability transitions. ${ }^{5}$ The goal was to bring into focus changes in the causes and levels of disability, and the distribution of disablement within different segments of the population. ${ }^{3}$

India is the second largest populated country in the world with 1.2 billion population ${ }^{1}$ and experiencing demographic and epidemiological transition. The country has experienced rapid demographic and epidemiological transition during the last two decades. While there has been significant improvement in the health and well-being of the population, the fertility level is nearing replacement. The growth rate of the elderly population is at least twice that of the overall population. Life expectancy at birth in India has increased from 54 years in 1981 to 67 years in $2011 .{ }^{9}$ Though people are living longer, the extent of disability has also increased. The increased in disability would determine not only the current health status of the population but also the state of public health of the nation. Though the pattern of increasing longevity has been experienced across low and middle-income countries (LMICs), studies suggest the additional years gained are coupled with increased period of morbidity (known as the 'compression of morbidity' Fries, 1980). Despite significant gains in total life expectancy, there are considerable social and health inequalities and inadequate access to health care in rural and less developed areas of the country.

A number of summary measures are used to quantify the extent of disability. Disability-free life expectancy (DFLE) is one such measures of 'health expectancy' and is a composite indicator combining information on mortality and morbidity. ${ }^{10}$ It is estimated by calculation of life expectancy for different health states with adjustment for severity weights. ${ }^{11} \mathrm{~A}$ few studies dealt with the type of disability in India from perspective of mortality and disability changes. A study in India found that DFLE has declined in advanced states and concludes that mere increase in longevity does not mean a better life. ${ }^{12}$ The factors explaining variation in DFLE may vary between men and women. Socioeconomic factors and health care resources play essential roles in variations in DFLE. Disability-Free Life Expectancy (DFLE) indicators show large variations geographically which can be explained by socioeconomic factors and may help in the formulation of health policy. ${ }^{13}$ Though studies in India estimates the disability; no attempt has been made to quantify the variation in DFLE by gender, place of residence and geographic region. In this context, the aim of this paper is to estimate the DFLE among disabled by place of residence and states of India.

Data: There are conceptual differences, data and methodological limitations in disability studies. The questions on disability are not consistent across census and surveys among and within counries. This study is predominantly based on data from the ${ }^{1}$ and the Sample Registration System (SRS). The ${ }^{1}$ collects data on eight categories of disability: 1) seeing disability, 2) hearing disability, 3) speech disability, 4) movement disability, 5) mental retardation, 6) mental illness, 7) any other disability, and 8) multiple disabilities. The three types of disability, i.e., mental retardation, mental illness, and any other disability were introduced for the first time in census questionnaire of 2011. Table C-20 provides data on disability disaggregated by ten-year age group. The SRS was initiated in the year 1964-65, and since then it has been collecting data on birth and death annually. The SRS based abridged Life-Tables are provided based on age-specific death rate (ASDR). We have used the SRS based abridged life table in estimating DFLE.

\section{Methodology}

Disability free life expectancy DFLE represents the expected number of years of remaining disability-free life a member of the life table cohort would experience if cohort age-specific rates of mortality and disability prevailed throughout his/her lifetime. The basic idea of the method is to combine the period life table, which is the primary method to calculate life expectancy, with the age-specific disability prevalence estimated from cross-sectional survey or census data. This calculation used institutionalization rates provided by census data and the prevalence of disability by their types. The total number of years lived by the population between given ages are calculated from a mortality table and the number of years without a disability is deduced from prevalence from census 2011. The number of years spent without a disability is thus estimated and accumulated from a starting point and then divided by the number of survivors at that age, thus giving an estimate of disability-free life expectancy at a given age. It can be estimated by calculation of life expectancy for different health states with adjustment for severity weights.

Sullivan's method estimates DFLE by partitioning the person-years lived in a given age interval into the proportion with and without a disability. The Sullivan health expectancy reflects the current health of a real population adjusted for mortality levels and independent of age structure. Health expectancy is the number of remaining years, at a particular age, which an individual can expect to live in a healthy state. ${ }^{14}$ The following steps are used in estimating DFLE.

1. The estimation was carried out for 10-year age groups. The final open-ended group of $90+$ was assumed of length 10 years.

2 . We calculated the prevalence $\left(\pi_{\mathrm{x}}\right)$ for all types of disability and prevalence of persons without disability from that, i.e. $\left(1-\pi_{\mathrm{x}}\right)$ given by. ${ }^{1}$

3. Since the abridged life-Table of Sample Registration System is in 5year age interval, we calculated $\mathrm{L}_{\mathrm{x}}$ (Person-years lived in each age interval) for 10-year age interval.

4. To get the person-years lived without disability we multiply the person-years lived at that age $\mathrm{L}_{\mathrm{x}}$ by the proportion of people without disability at that age $\left(1-\pi_{\mathrm{x}}\right)$.

5. The total number of years lived from the particular age is $T_{x}$. This column is calculated by summing all the entries of $L_{x}$ column, from that age to age $90+$ years.

$\mathrm{T}_{\mathrm{x}}=\sum\left[1-\pi_{x}\right] L_{x}$

6. Similarly, the DFLE at each age interval is found by dividing the total number of years lived in $\mathrm{T}_{\mathrm{x}}$ from that age by the probability of surviving to that age $l_{\mathrm{x}}$.

$\operatorname{DFLE}_{\mathrm{x}}=\frac{T_{x}}{l_{x}}$

7. Since the Sullivan health expectancy combines such mortality and disability rates, it too is subject to random variation. To assess the size of this random variation, we shall calculate the standard error of DFLE.

8. ${ }^{15}$ shows that the variances of DFLE can be approximated by:

$\mathrm{S}^{2}\left(\mathrm{DFLE}_{\mathrm{x}}\right)=\frac{1}{l^{2}} \sum_{x=0}^{w} L_{x}^{2} S^{2}\left(1-\pi_{x}\right)$

9. Furthermore, approximate 95\% confidence intervals for the DFLE are calculated using standard error, $D^{2} E_{x} \pm 1.96 * S\left(D^{2} E_{x}\right)$.

The analysis was carried out for major states of India for which SRS provides the Life-Table. For gender differentials, DFLE was calculated for males and females separately, further for regional disparity DFLE was calculated for urban and rural areas separately. DFLE was also calculated for eight types of disability to find out the contribution of each disability in the reduction of life expectancy. 
Table 1

Life expectancy disability-free life expectancy and years living with disability by type of disability in India, 2011.

\begin{tabular}{|c|c|c|c|c|c|c|c|c|c|c|}
\hline Age group & Life expectancy & DFLE & Seeing & Hearing & Speech & Movement & Mental retardation & Mental Illness & Any other & Multiple \\
\hline $0-9$ & 68.34 & 59.38 & 59.61 & 59.48 & 59.03 & 59.26 & 58.88 & 58.81 & 59.32 & 59.90 \\
\hline 10-19 & 66.94 & 58.12 & 58.39 & 58.34 & 57.76 & 57.68 & 57.60 & 57.15 & 58.29 & 58.69 \\
\hline $20-29$ & 57.41 & 50.25 & 50.34 & 50.47 & 50.37 & 49.41 & 50.74 & 48.95 & 50.52 & 51.05 \\
\hline $30-39$ & 48.08 & 42.41 & 42.17 & 42.54 & 42.78 & 41.71 & 43.40 & 41.26 & 42.78 & 42.99 \\
\hline $40-49$ & 38.87 & 34.48 & 33.98 & 34.55 & 35.07 & 33.89 & 35.72 & 33.98 & 34.95 & 34.67 \\
\hline $50-59$ & 29.98 & 26.63 & 26.02 & 26.66 & 27.35 & 26.10 & 27.89 & 26.83 & 27.16 & 26.43 \\
\hline $60-69$ & 21.74 & 19.12 & 18.58 & 19.12 & 19.81 & 18.73 & 20.16 & 19.61 & 19.64 & 18.64 \\
\hline $70-79$ & 14.57 & 12.59 & 12.32 & 12.56 & 13.00 & 12.41 & 13.13 & 12.93 & 12.92 & 12.05 \\
\hline 80-89 & 8.88 & 6.79 & 6.74 & 6.78 & 6.93 & 6.76 & 6.95 & 6.91 & 6.90 & 6.53 \\
\hline
\end{tabular}

\section{Results}

Table 1, presents the life expectancy and disability-free life expectancy by type of disability in India for 2011 . With the increase in age, the life expectancy, as well as disability-free life expectancy, decreases, and the difference between two narrow down. At the national level, life expectancy at birth was 68.3 years and disability-free life expectancy was 59.4 years. The difference between life expectancy and DFLE provides the years lived with disability. The DFLE by type of disability was lowest for mental illness ( 58.8 years) followed by mental retardation ( 58.9 years). There are not much variation in DFLE by other types of disability. Fig. 1 presents the life expectancy and disability-free life expectancy with $95 \%$ confidence interval in India. It is clear from the graph that the difference between LE and DFLE declines with age. Also, the confidence interval of DFLE narrowed over age.

Fig. 2 shows the male female differential in life expectancy and disability-free life expectancy with $95 \%$ confidence interval in India. Disability-free life expectancy and life expectancy differ by gender. It show that female have higher life expectancy and disability free life expectancy compare to male in India. Table 2, presents the life expectancy and disability-free life expectancy along with the types of disability among male and female by age. The disability-free life expectancy was longer for females than males for all types of disability. Among males, disability-free life expectancy at age zero was highest for movement disability (58.9 years) followed by multiple disabilities (58.51 years) and seeing disability (57.8 years) and lowest among speech disability (57.2 years) followed by any other type of disability (58.3 years). Among females, disability-free life expectancy was highest in multiple disabilities (61.38 years) followed by seeing (61.0 years) and lowest in mental retardation (60.3 years). As the population ages, the difference between disability-free life expectancy and life expectancy narrows down for males as well as females.

Fig. 3 shows the urban-rural differential in life expectancy and disability-free life expectancy with $95 \%$ confidence interval in India. Table 3, presents the rural-urban differential of disability-free life expectancy by the type of disability in India. In rural India, disability-free life expectancy was 58.4 years at age zero. Persons with multiple disabilities have a a highest disability-free life expectancy (58.9 years) followed by seeing disability (58.7 years) in age interval $0-9$ years. Similarly, for urban areas disability-free life expectancy was 62.2 years at age zero, and among all type of disabilities, disability-free life expectancy is lowest among persons suffering from mental retardation (61.9 years). Life expectancy, as well as disability-free life expectancy both, are high in urban areas. Females are having a longer life expectancy and disability-free life expectancy in comparison to their male counterparts.

Table 4, presents the life expectancy and disability-free life expectancy for major states of India. In the northern region, life expectancy and disability-free life expectancy for states of Jammu and Kashmir. In the age group 0-9 years, the life expectancy is 73.2 years and DFLE was 62.5 year, For Himachal Pradesh disability-free life expectancy and life expectancy at $0-9$ years was 62.3 years and 72.0 years

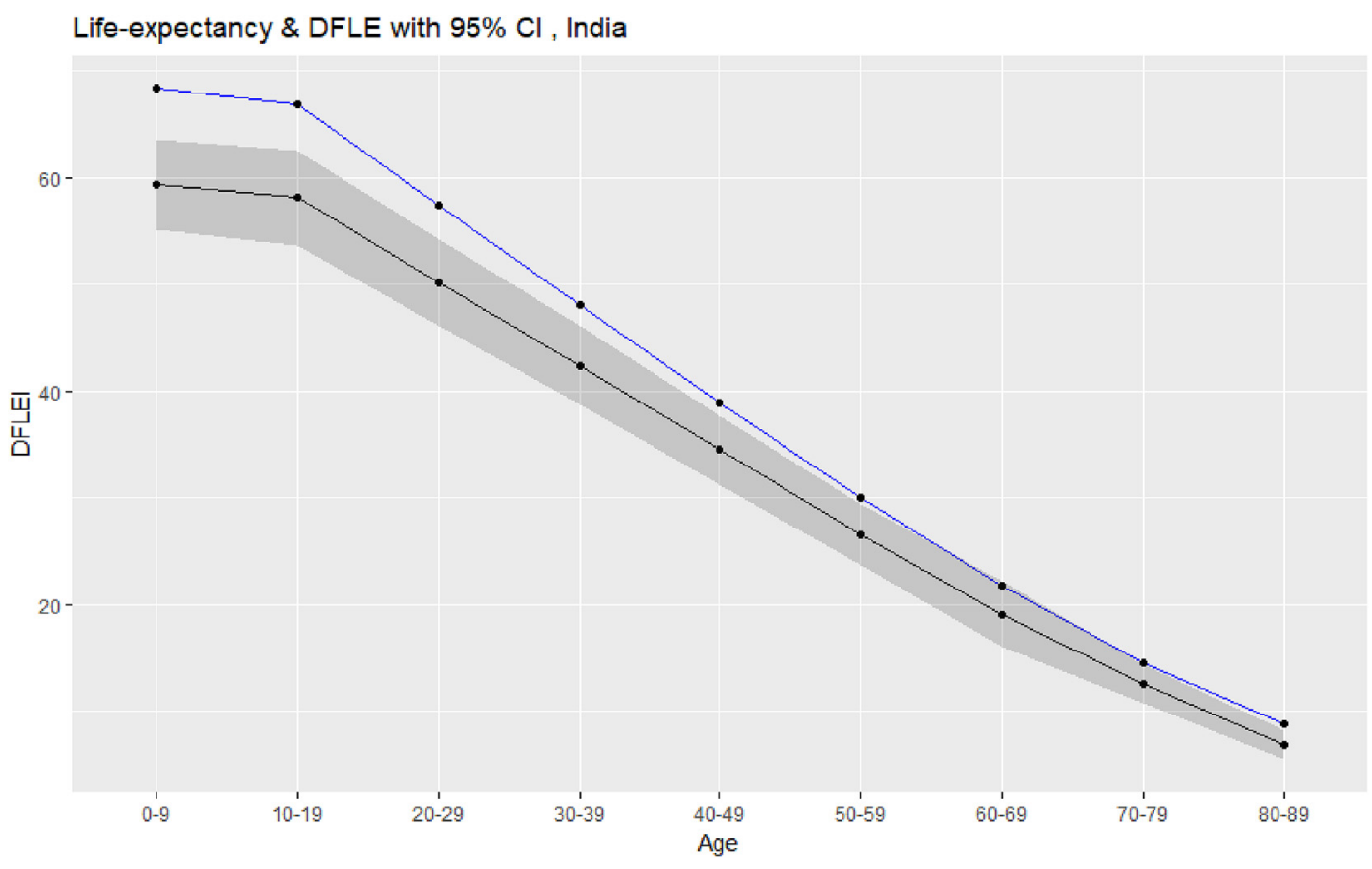

Fig. 1. Life expectancy and DFLE with $95 \%$ confidence interval by age in India. 

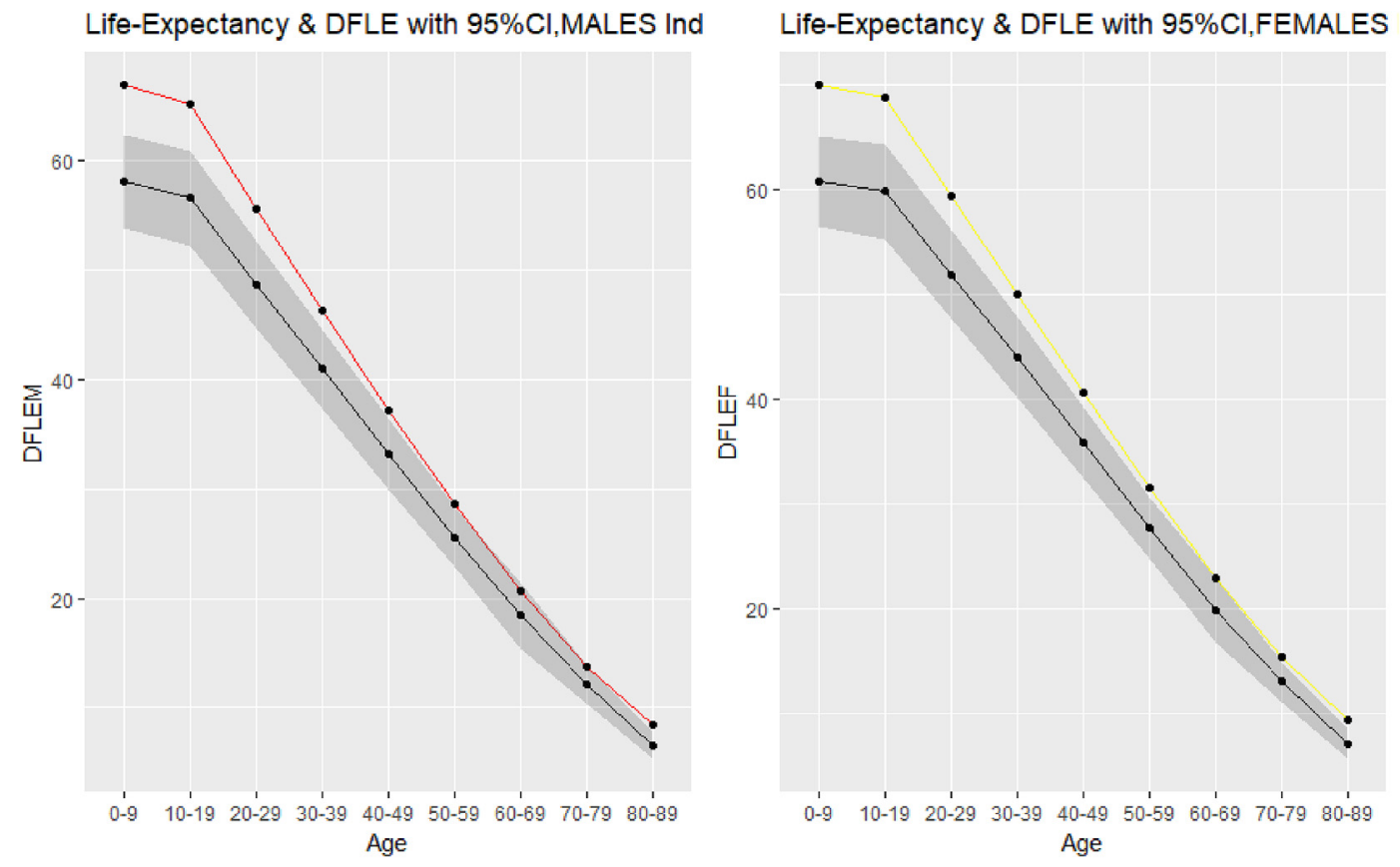

Fig. 2. Male female differential in life expectancy and disability-free life expectancy with $95 \%$ confidence interval in India.

respectively, and for age interval, $80-89$ years age group it was 7.0 years and 10.6 years respectively. Similarly, for Punjab, Haryana and Rajasthan, disability-free life expectancy at age zero was 62.0 years, 59.7 years and 59.3 years respectively. In the northern region of India, Uttar Pradesh has the lowest disability-free life expectancy of 56.1 years followed by Madhya Pradesh 56.4 years and Bihar 59.8 years for the age interval of 0-9 years. Similarly, for Jharkhand, Uttarakhand and Chhattisgarh disability-free life expectancy at age zero is 58.6 years, 61.2 years and 62.1 years respectively.

In the southern part of India, both life expectancy and disability-free life expectancy both are high. Kerala has the highest life expectancy and disability-free life expectancy at age zero 75.2 years and 65.0 years respectively. In Tamil Nadu. The life expectancy and disability-free life expectancy at age zero of 71.0 years and 61.4 years. Whereas, Andhra Pradesh and Karnataka have 59.6 years and 60.0 years value of disability-free life expectancy at age zero. In the western region of the country, Maharashtra and Gujarat have a disability-free life expectancy of 62.4 years and 59.9 years respectively. The distribution of disabilityfree life expectancy in states of eastern zone are as follows; Assam has the lowest magnitude of disability-free life expectancy 56.4 years and life expectancy of 64.7 years, followed by Odisha and West Bengal.

Table 5, presents the number of years a person lives with a disability (LWD), i.e., the difference between life expectancy and disability-free life expectancy, by the type of disability in major states of India. In India life lived with a disability was highest at age zero; 8.96 years and it declines with an increase in ag. Persons those are suffering from mental illness spend 9.53 years of life with a disability at age zero followed by persons who are mentally retarded ( 9.46 years). Among all the eight types of disabilities persons having multiple disabilities have least (8.44 years) years of life lived with disability for the age interval 0-9 years. In the northern region, Jammu and Kashmir life lived with a disability is highest among persons suffering from mental illness 11.3 years, followed by mental retardation of 11.13 years and speech disability of 11.0 years at age zero. A life lived with a disability was lowest

Table 2

Life expectancy and disability-free life expectancy by type of disability by male and female in India, 2011.

\begin{tabular}{|c|c|c|c|c|c|c|c|c|c|}
\hline Age group & Life expectancy & Seeing & Hearing & Speech & Movement & Mental retardation & Mental Illness & Any other & Multiple \\
\hline \multicolumn{10}{|l|}{ Male } \\
\hline 0-9 & 66.87 & 58.34 & 58.23 & 57.79 & 58.88 & 57.60 & 57.52 & 58.05 & 58.51 \\
\hline $10-19$ & 65.20 & 56.89 & 56.84 & 56.29 & 57.60 & 56.08 & 55.64 & 56.76 & 57.11 \\
\hline $20-29$ & 55.66 & 48.90 & 49.00 & 48.92 & 50.74 & 49.24 & 47.46 & 48.96 & 49.63 \\
\hline $30-39$ & 46.33 & 40.79 & 41.09 & 41.31 & 43.40 & 41.93 & 39.88 & 41.23 & 41.67 \\
\hline $40-49$ & 37.25 & 32.77 & 33.24 & 33.68 & 35.72 & 34.36 & 32.80 & 33.53 & 33.53 \\
\hline $50-59$ & 28.58 & 25.11 & 25.62 & 26.20 & 27.89 & 26.78 & 25.90 & 26.02 & 25.59 \\
\hline $60-69$ & 20.63 & 17.94 & 18.36 & 18.95 & 20.16 & 19.31 & 18.89 & 18.80 & 18.10 \\
\hline $70-79$ & 13.80 & 11.91 & 12.08 & 12.47 & 13.13 & 12.61 & 12.46 & 12.40 & 11.76 \\
\hline $80-89$ & 8.39 & 6.54 & 6.57 & 6.70 & 6.95 & 6.72 & 6.70 & 6.68 & 6.41 \\
\hline \multicolumn{10}{|l|}{ Female } \\
\hline $0-9$ & 69.96 & 60.969 & 60.83 & 60.37 & 60.71 & 60.27 & 60.20 & 60.70 & 61.38 \\
\hline $10-19$ & 68.87 & 60.013 & 59.97 & 59.36 & 59.43 & 59.27 & 58.79 & 59.99 & 60.39 \\
\hline $20-29$ & 59.34 & 51.903 & 52.08 & 51.95 & 51.17 & 52.38 & 50.57 & 52.25 & 52.57 \\
\hline $30-39$ & 50.02 & 43.661 & 44.12 & 44.40 & 43.37 & 44.99 & 42.73 & 44.50 & 44.38 \\
\hline $40-49$ & 40.67 & 35.273 & 35.98 & 36.59 & 35.30 & 37.18 & 35.20 & 36.50 & 35.85 \\
\hline 50-59 & 31.50 & 26.982 & 27.77 & 28.59 & 27.07 & 29.07 & 27.77 & 28.39 & 27.27 \\
\hline $60-69$ & 22.91 & 19.200 & 19.90 & 20.70 & 19.29 & 21.00 & 20.29 & 20.51 & 19.11 \\
\hline $70-79$ & 15.37 & 12.721 & 13.05 & 13.54 & 12.72 & 13.65 & 13.38 & 13.44 & 12.27 \\
\hline $80-89$ & 9.37 & 6.912 & 6.98 & 7.14 & 6.89 & 7.16 & 7.10 & 7.11 & 6.61 \\
\hline
\end{tabular}



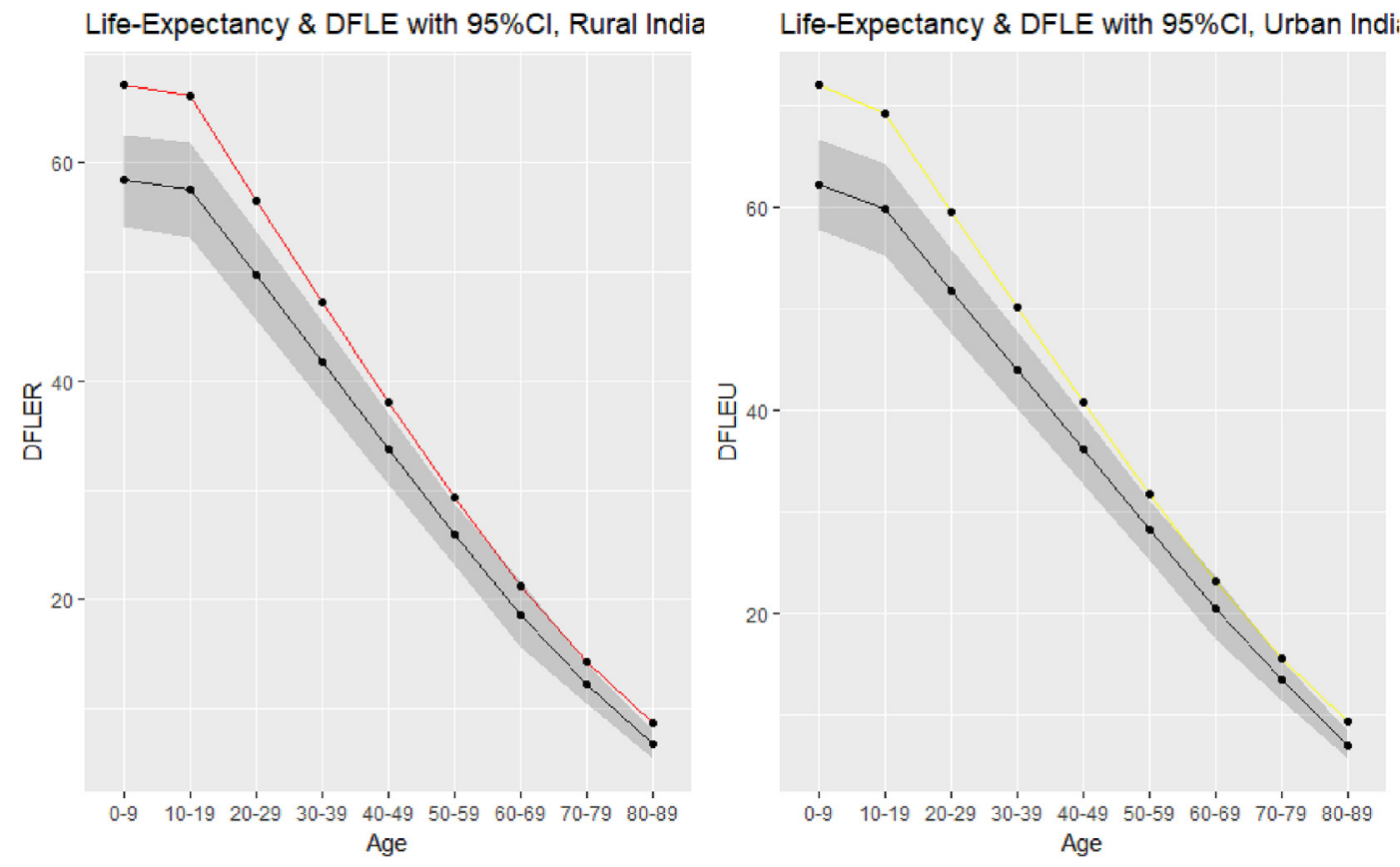

Fig. 3. Urban rural differential in life expectancy and disability-free life expectancy with $95 \%$ confidence interval in India.

Table 3

Rural-urban differential of disability-free life expectancy by type of disability in India, 2011.

\begin{tabular}{|c|c|c|c|c|c|c|c|c|c|}
\hline Rural & DFLE & Seeing & Hearing & Speech & Movement & Mental Retardation & Mental Illness & Another & Multiple \\
\hline $0-9$ & 58.38 & 58.67 & 58.51 & 57.99 & 58.24 & 57.81 & 57.74 & 58.29 & 58.94 \\
\hline $10-19$ & 57.48 & 57.80 & 57.73 & 57.12 & 57.02 & 56.89 & 56.42 & 57.65 & 58.08 \\
\hline $20-29$ & 49.68 & 49.76 & 49.92 & 49.93 & 48.84 & 50.16 & 48.31 & 49.97 & 50.43 \\
\hline $30-39$ & 41.78 & 41.46 & 41.87 & 42.32 & 41.15 & 42.76 & 40.64 & 42.16 & 42.32 \\
\hline $40-49$ & 33.83 & 33.22 & 33.85 & 34.58 & 33.34 & 35.11 & 33.41 & 34.33 & 33.99 \\
\hline $50-59$ & 25.99 & 25.27 & 25.98 & 26.86 & 25.57 & 27.34 & 26.31 & 26.59 & 25.79 \\
\hline $60-69$ & 18.57 & 17.91 & 18.54 & 19.39 & 18.27 & 19.71 & 19.18 & 19.16 & 18.08 \\
\hline $70-79$ & 12.26 & 11.93 & 12.23 & 12.75 & 12.13 & 12.87 & 12.68 & 12.64 & 11.69 \\
\hline $80-89$ & 6.70 & 6.62 & 6.69 & 6.85 & 6.67 & 6.87 & 6.83 & 6.82 & 6.42 \\
\hline \multicolumn{10}{|l|}{ Urban } \\
\hline $0-9$ & 62.19 & 62.31 & 62.28 & 61.93 & 62.09 & 61.86 & 61.77 & 62.21 & 62.55 \\
\hline 10-19 & 59.72 & 59.91 & 59.91 & 59.38 & 59.30 & 59.36 & 58.94 & 59.94 & 60.16 \\
\hline $20-29$ & 51.69 & 51.83 & 51.91 & 51.58 & 50.73 & 52.20 & 50.53 & 51.94 & 52.56 \\
\hline $30-39$ & 43.98 & 43.92 & 44.18 & 44.03 & 43.00 & 44.94 & 42.77 & 44.30 & 44.66 \\
\hline 40-49 & 36.09 & 35.84 & 36.25 & 36.33 & 35.23 & 37.21 & 35.37 & 36.45 & 36.39 \\
\hline 50-59 & 28.19 & 27.89 & 28.31 & 28.58 & 27.43 & 29.25 & 28.12 & 28.58 & 28.12 \\
\hline $60-69$ & 20.51 & 20.26 & 20.55 & 20.91 & 19.96 & 21.28 & 20.71 & 20.86 & 20.17 \\
\hline 70-79 & 13.43 & 13.32 & 13.41 & 13.67 & 13.18 & 13.81 & 13.60 & 13.64 & 13.06 \\
\hline $80-89$ & 7.05 & 7.03 & 7.03 & 7.13 & 6.99 & 7.16 & 7.11 & 7.12 & 6.86 \\
\hline
\end{tabular}

among people suffering from multiple disabilities. A similar trend was found in other states of the northern region, like Himachal Pradesh, Punjab, Haryana, and Rajasthan. For Himachal Pradesh life lived with a disability was highest for mental illness (10.85 years) for the age interval 10-19 years and lowest for multiple disability 9.0 years. A life lived with disability for Punjab state was 10.0 years, for mental retardation life lived with disability 10.5 years. Similarly, for Haryana life lived with a disability is 9.4 years.

In northern region state like Uttar Pradesh (8.28 years) had least years of life lived with disability in comparison to other states. A life lived with a disability was highest for mental illness (8.90 years). Similarly, for Bihar and Madhya Pradesh life lived with a disability was 8.60 years and 8.30 years respectively, and persons with mental illness suffer more from disability in both states. Other smaller states in this region like Uttarakhand, Delhi, Jharkhand, and Chhattisgarh have a distribution of life lived with disability in a similar manner.

In the southern region of the country Andhra Pradesh had a magnitude of 9.42 years of life lived with disability, persons in the age group 10-19 years age group suffer more with a disability from mental illness (10.1 years). In Karnataka life lived with a disability was 8.93 years, whereas it is highest for mental illness (9.53 years) in 10-19 years age group, followed by mental retardation ( 9.28 years) and movement disability ( 9.13 years). In Kerala life lived with a disability is highest in 10-19 years age group among persons suffering from mental retardation (10.60 years) and lowest among seeing disability 9.77 years in 0-9 year's age group. Similarly, in Tamil Nadu, life lived with a disability is highest in 10-19 years age group among persons suffering from mental retardation (10.2 years) and lowest among seeing disability ( 9.35 years) in the $0-9$ year's age group. In the western region, Maharashtra and Gujarat have 9.23 years and 9.67 years of life lived with disability.

Fig. 4 shows the proportion of disability-free life expectancy by gender and age group in India. It show that proportion of life spent disability free was higher for male than female across all age group. Fig. 5 presents the proportion of life spent disability-free by type of disability in India. The proportion of life spent disability-free was 
Table 4

Life expectancy and disability free life expectancy by age group in major states of India, 2011.

\begin{tabular}{|c|c|c|c|c|c|c|c|c|c|c|c|c|c|c|c|c|c|c|}
\hline \multirow{2}{*}{ States } & \multicolumn{9}{|c|}{ Life expectancy } & \multicolumn{9}{|c|}{ Disability-free life expectancy } \\
\hline & $0-9$ & $10-19$ & $20-29$ & $30-39$ & $40-49$ & $50-59$ & $60-69$ & 70-79 & $80-89$ & $0-9$ & $10-19$ & $20-29$ & $30-39$ & $40-49$ & $50-59$ & $60-69$ & $70-79$ & $80-89$ \\
\hline Jammu \& Kashmir & 73.15 & 71.6 & 61.98 & 52.42 & 42.99 & 33.89 & 25.32 & 18.04 & 12.19 & 62.46 & 60.99 & 52.93 & 44.77 & 36.55 & 28.47 & 20.6 & 13.77 & 7.45 \\
\hline Himachal Pradesh & 72 & 70.37 & 60.64 & 51.13 & 41.72 & 32.6 & 24.08 & 16.42 & 10.64 & 62.29 & 60.6 & 52.07 & 43.75 & 35.56 & 27.49 & 19.81 & 12.88 & 7.02 \\
\hline Punjab & 72.08 & 69.36 & 59.66 & 50.36 & 41.18 & 32.36 & 24.22 & 16.82 & 10.68 & 62.02 & 59.5 & 51.37 & 43.78 & 36.02 & 28.3 & 20.82 & 13.94 & 7.49 \\
\hline Haryana & 69.13 & 67.71 & 58.03 & 48.71 & 39.56 & 30.7 & 22.58 & 15.66 & 10.26 & 59.73 & 58.36 & 50.25 & 42.45 & 34.56 & 26.69 & 19.22 & 12.86 & 7.09 \\
\hline Rajasthan & 67.93 & 67.51 & 58.02 & 48.67 & 39.45 & 30.55 & 22.33 & 15.17 & 9.52 & 59.32 & 58.78 & 50.62 & 42.4 & 34.13 & 26 & 18.39 & 12.05 & 6.71 \\
\hline Uttar Pradesh & 64.47 & 64.7 & 55.23 & 45.93 & 36.76 & 28.01 & 20.09 & 13.51 & 8.06 & 56.19 & 56.53 & 49.2 & 41.45 & 33.48 & 25.6 & 18.24 & 12.15 & 6.6 \\
\hline Bihar & 68.44 & 66.94 & 57.48 & 48.07 & 38.79 & 29.73 & 21.12 & 13.67 & 7.87 & 59.83 & 58.86 & 51.44 & 43.47 & 35.43 & 27.29 & 19.33 & 12.49 & 6.6 \\
\hline Assam & 64.73 & 64.43 & 54.98 & 45.65 & 36.57 & 27.73 & 19.79 & 13.12 & 8.02 & 56.48 & 56.18 & 48.26 & 40.3 & 32.42 & 24.66 & 17.47 & 11.42 & 6.26 \\
\hline West Bengal & 70.49 & 67.93 & 58.28 & 48.82 & 39.43 & 30.28 & 21.81 & 14.41 & 8.67 & 61.16 & 58.81 & 50.78 & 42.83 & 34.77 & 26.89 & 19.35 & 12.61 & 6.73 \\
\hline Odisha & 66.87 & 66.12 & 56.81 & 47.65 & 38.58 & 29.79 & 21.7 & 14.59 & 9.38 & 58.02 & 57.24 & 49.35 & 41.42 & 33.45 & 25.68 & 18.33 & 12.01 & 6.67 \\
\hline Madhya Pradesh & 64.76 & 64.85 & 55.54 & 46.51 & 37.45 & 28.56 & 20.43 & 13.26 & 7.98 & 56.46 & 56.51 & 48.88 & 41.32 & 33.49 & 25.58 & 18.1 & 11.57 & 6.26 \\
\hline Gujarat & 69.1 & 67.89 & 58.32 & 49 & 39.76 & 30.82 & 22.62 & 15.37 & 9.42 & 59.87 & 58.74 & 50.82 & 43.06 & 35.24 & 27.42 & 19.98 & 13.22 & 7.11 \\
\hline Maharashtra & 72.02 & 68.71 & 59.01 & 49.6 & 40.38 & 31.42 & 23 & 15.44 & 9.28 & 59.87 & 58.74 & 50.82 & 43.06 & 35.24 & 27.42 & 19.98 & 13.22 & 7.11 \\
\hline Andhra Pradesh & 69.05 & 66.84 & 57.14 & 47.77 & 38.69 & 30.07 & 21.99 & 15.04 & 9.63 & 62.36 & 59.39 & 51.31 & 43.49 & 35.7 & 27.9 & 20.27 & 13.31 & 7.03 \\
\hline Karnataka & 68.99 & 66.53 & 56.87 & 47.5 & 38.33 & 29.55 & 21.32 & 14.07 & 8.01 & 59.63 & 57.51 & 49.29 & 41.48 & 33.71 & 26.15 & 18.83 & 12.65 & 6.96 \\
\hline Kerala & 75.2 & 71.17 & 61.32 & 51.71 & 42.19 & 32.94 & 24.25 & 16.5 & 10 & 60.06 & 57.84 & 49.94 & 42.34 & 34.55 & 26.84 & 19.35 & 12.69 & 6.66 \\
\hline West Bengal & 70.49 & 67.93 & 58.28 & 48.82 & 39.43 & 30.28 & 21.81 & 14.41 & 8.67 & 65.07 & 61.2 & 52.33 & 43.8 & 35.56 & 27.72 & 20.25 & 13.4 & 7.08 \\
\hline Odisha & 66.87 & 66.12 & 56.81 & 47.65 & 38.58 & 29.79 & 21.7 & 14.59 & 9.38 & 61.16 & 58.81 & 50.78 & 42.83 & 34.77 & 26.89 & 19.35 & 12.61 & 6.73 \\
\hline Tamil Nadu & 71 & 67.68 & 58.01 & 48.68 & 39.41 & 30.47 & 22.18 & 14.8 & 8.91 & 61.39 & 58.28 & 50.04 & 42.45 & 34.77 & 27.13 & 19.75 & 12.97 & 6.88 \\
\hline Uttarakhand & 71.76 & 69.15 & 59.48 & 50.11 & 40.84 & 32.07 & 24.07 & 17.02 & 12.05 & 61.24 & 58.81 & 50.83 & 42.93 & 34.78 & 26.92 & 19.48 & 12.84 & 7.08 \\
\hline Delhi & 73.81 & 70.62 & 60.91 & 51.47 & 42.1 & 32.84 & 24.2 & 16.62 & 10.25 & 63.74 & 60.78 & 52.65 & 44.85 & 36.8 & 28.65 & 20.79 & 13.88 & 7.42 \\
\hline Jharkhand & 67.24 & 65.54 & 56.18 & 46.85 & 37.69 & 28.85 & 20.75 & 13.7 & 8.34 & 58.59 & 57.21 & 49.66 & 41.71 & 33.7 & 25.82 & 18.43 & 12.12 & 6.65 \\
\hline Chhattisgarh & 71.67 & 68.73 & 59.05 & 49.61 & 40.44 & 31.48 & 23.2 & 15.88 & 9.8 & 62.1 & 59.36 & 51.14 & 43.06 & 35 & 27.01 & 19.46 & 13.04 & 7.08 \\
\hline
\end{tabular}

higher in mental retardation followed by speech and any other disability.

\section{Discussion}

The disability-free life expectancy was provides better understanding of health and disability of a population. It is useful to understand whether an increased life expectancy is associated with an increase or decrease in disability. ${ }^{16}$ This is the first ever study that provides the estimates of DFLE by type of disability across major states of India. Our study extends earlier literature $e^{17-21}$ on disability-free life expectancy by focusing on gender and regional in India. The followings are the salient findings of the paper.

First, the DFLE in India was about 9 years lower than that of life expectancy at birth. The gap was persistent across all age group and across states of India. Second, the DFLE was lowest for mental illness followed by mental retardation. This holds true across age group, sex and region. Third, the gender differentials in life expectancy and DFLE is consistent in India and states. In general, the prevalence of disability and years lived with disability was higher among women than men. Although women live longer, they spend a more substantial amount of time with disability. Fourth, life expectancy and DFLE varied considerably in states of India with the lowest estimate in the state of Assam and highest in Jammu and Kashmir. The poorer states of Bihar, Uttar Pradesh, West Bengal, and Madhya Pradesh have low DFLE while better off states such as Punjab and Haryana have higher disability-free life expectancy in India.

The substantial differential in life expectancy and disability-free life expectancy was found across states and gender at birth and at higher age is consistent with literaure. Studies also suggests that the Inequalities in disability-free life expectancy much higher than in life expectancy. Inequality in life expectancy has increased over time. Inequality in disability-free life expectancy fell slightly for males at birth.

We provide some plausible explanation to our findings. First, the high DFLE may be attributed to increase in longevity across all ages, changing disease pattern, age at onset of diseases, increasing injuries and accident, accessibility and use of health services. The prevalence of disability can increase if survival of the disabled increases, even though the likelihood of becoming disabled stays the same. Second, higher DFLE among females may be attributed to their higher life expectancy, higher morbidity and lower social status. At older age, over half of the women are widowed and lack resources for health care. Third, the low DFLE in poorer states of India may be due to high prevalence of poverty and lack of access to health care. Poverty and disability are highly correlated and may explain the regional pattern of DFLE in India. ${ }^{3}$ Fourth, the nature and extent of disability varies by type of disability. People with mental 58.88 have low DFLE may be because of low health and severity of disability.

Despite these, we put forward the following limitations of this study. First, we have used the data from census of India that may have underestimate the extent of disability. For example, the recent National Mental Health Survey, 2016 estimated the mental disability at $0.7 \%$. Second, the census data was for 2011 and does not provide the determinants and risk factor of disability. Hence, we have not explored the determinants and risk factors of disability.

\subsection{Policy implications}

The gap between life expectancy and DFLE can be reduced by reducing the extent of disability in the population. While one fifth of the disability are accoutred at birth, over four-fifth of the disability are post birth; largely due to disease, accident and injuries. The early onset of non-communicable diseases are the main force of increasing disability at later ages. Similarly, increasing attention should be paid to immediate treatment of injuries and accident and mental diseases that occur at early ages. Finally, though the national and state government provides some benefits to the disabled, more attention may be given for infrastructural development. These includes creating disable friendly infrastructure in offices and public places.

\section{Conclusion}

The gap in life expectancy and DFLE persists at all ages and states of India. The prevalence of disability was higher in both sexes in India, and it occurred at a younger age.The low DFLE in the poorere state of Uttar Pradesh, Odisha, and Assam suggest poverty gradient of disability. Males with movement disability were found to have a longer 
Table 5

Live lived with disability by the type of disability in major state of India, 2011.

\begin{tabular}{|c|c|c|c|c|c|c|c|c|c|}
\hline Age & Total & Seeing & Hearing & Speech & Movement & Mental Retardation & Mental Illness & Any other & Multiple \\
\hline \multicolumn{10}{|l|}{ India } \\
\hline $0-9$ & 8.96 & 8.73 & 8.86 & 9.31 & 9.08 & 9.46 & 9.53 & 9.02 & 8.44 \\
\hline $10-19$ & 8.83 & 8.55 & 8.61 & 9.19 & 9.26 & 9.34 & 9.8 & 8.65 & 8.26 \\
\hline $20-29$ & 7.15 & 7.07 & 6.93 & 7.04 & 8 & 6.67 & 8.46 & 6.88 & 6.36 \\
\hline $30-39$ & 5.66 & 5.91 & 5.54 & 5.29 & 6.37 & 4.68 & 6.82 & 5.3 & 5.09 \\
\hline $40-49$ & 4.39 & 4.9 & 4.32 & 3.8 & 4.98 & 3.16 & 4.9 & 3.93 & 4.21 \\
\hline $50-59$ & 3.35 & 3.95 & 3.31 & 2.62 & 3.88 & 2.08 & 3.14 & 2.81 & 3.54 \\
\hline $60-69$ & 2.62 & 3.16 & 2.62 & 1.93 & 3.01 & 1.58 & 2.13 & 2.1 & 3.1 \\
\hline $70-79$ & 1.98 & 2.25 & 2.01 & 1.57 & 2.16 & 1.44 & 1.64 & 1.65 & 2.52 \\
\hline $80-89$ & 2.09 & 2.14 & 2.1 & 1.95 & 2.12 & 1.93 & 1.97 & 1.98 & 2.35 \\
\hline \multicolumn{10}{|c|}{ Jammu \& Kashmir } \\
\hline $0-9$ & 10.7 & 10.43 & 10.62 & 11 & 10.86 & 11.13 & 11.27 & 10.84 & 10.3 \\
\hline $10-19$ & 10.6 & 10.3 & 10.41 & 10.75 & 11.01 & 11.05 & 11.49 & 10.61 & 10.29 \\
\hline $20-29$ & 9.04 & 8.88 & 8.98 & 8.26 & 9.73 & 8.91 & 9.9 & 8.98 & 8.67 \\
\hline $30-39$ & 7.65 & 7.82 & 7.51 & 6.69 & 8.34 & 7.08 & 8.22 & 7.4 & 7.5 \\
\hline $40-49$ & 6.44 & 6.93 & 6.26 & 5.31 & 7 & 5.53 & 6.53 & 6.07 & 6.59 \\
\hline $50-59$ & 5.42 & 6.09 & 5.29 & 4.19 & 5.86 & 4.27 & 4.99 & 4.96 & 5.84 \\
\hline $60-69$ & 4.72 & 5.32 & 4.66 & 3.68 & 4.97 & 3.68 & 4.1 & 4.22 & 5.37 \\
\hline $70-79$ & 4.27 & 4.65 & 4.26 & 3.63 & 4.35 & 3.64 & 3.8 & 3.88 & 4.89 \\
\hline $80-89$ & 4.74 & 4.86 & 4.73 & 4.52 & 4.73 & 4.53 & 4.56 & 4.58 & 5.02 \\
\hline \multicolumn{10}{|l|}{ Punjab } \\
\hline $0-9$ & 10.06 & 9.66 & 9.92 & 10.21 & 10.29 & 10.47 & 10.33 & 10.12 & 9.65 \\
\hline $10-19$ & 9.85 & 9.44 & 9.57 & 9.92 & 10.4 & 10.3 & 10.43 & 9.8 & 9.3 \\
\hline $20-29$ & 8.29 & 8.08 & 7.95 & 7.68 & 9.34 & 7.91 & 9.22 & 8.2 & 7.18 \\
\hline $30-39$ & 6.59 & 6.89 & 6.29 & 5.95 & 7.3 & 5.86 & 7.67 & 6.49 & 5.69 \\
\hline $40-49$ & 5.16 & 5.93 & 4.97 & 4.59 & 5.39 & 4.27 & 5.96 & 5.1 & 4.69 \\
\hline 50-59 & 4.06 & 5.01 & 3.93 & 3.53 & 4.28 & 3.08 & 4.36 & 3.87 & 3.92 \\
\hline $60-69$ & 3.4 & 4.3 & 3.32 & 2.93 & 3.6 & 2.56 & 3.45 & 3.12 & 3.53 \\
\hline $70-79$ & 2.88 & 3.39 & 2.89 & 2.62 & 2.96 & 2.42 & 2.82 & 2.66 & 3.14 \\
\hline $80-89$ & 3.19 & 3.37 & 3.22 & 3.09 & 3.21 & 3.03 & 3.15 & 3.09 & 3.36 \\
\hline \multicolumn{10}{|c|}{ Rajasthan } \\
\hline $0-9$ & 8.62 & 8.44 & 8.58 & 9.3 & 8.67 & 9.59 & 9.67 & 9.05 & 7.63 \\
\hline $10-19$ & 8.73 & 8.52 & 8.59 & 9.15 & 9.04 & 9.66 & 10.08 & 8.84 & 7.75 \\
\hline $20-29$ & 7.4 & 7.43 & 7.27 & 6.62 & 8.14 & 6.76 & 8.58 & 7.1 & 6.56 \\
\hline $30-39$ & 6.27 & 6.64 & 6.24 & 5.03 & 6.88 & 4.98 & 6.91 & 5.66 & 5.9 \\
\hline $40-49$ & 5.31 & 6 & 5.36 & 3.76 & 5.75 & 3.52 & 5.04 & 4.38 & 5.48 \\
\hline 50-59 & 4.54 & 5.34 & 4.61 & 2.76 & 4.99 & 2.42 & 3.32 & 3.32 & 5.18 \\
\hline $60-69$ & 3.95 & 4.64 & 4 & 2.19 & 4.35 & 1.9 & 2.38 & 2.62 & 4.97 \\
\hline $70-79$ & 3.12 & 3.41 & 3.1 & 1.93 & 3.38 & 1.78 & 1.95 & 2.15 & 4.26 \\
\hline $80-89$ & 2.81 & 2.82 & 2.78 & 2.4 & 2.87 & 2.37 & 2.4 & 2.46 & 3.41 \\
\hline \multicolumn{10}{|c|}{ Uttar Pradesh } \\
\hline $0-9$ & 8.28 & 8.02 & 8.21 & 8.59 & 8.51 & 8.79 & 8.9 & 8.3 & 7.72 \\
\hline $10-19$ & 8.17 & 7.85 & 7.93 & 8.56 & 8.86 & 8.85 & 9.26 & 7.98 & 7.64 \\
\hline $20-29$ & 6.03 & 6.02 & 5.8 & 5.96 & 6.79 & 5.98 & 6.99 & 5.84 & 5.41 \\
\hline $30-39$ & 4.47 & 4.81 & 4.32 & 4.27 & 4.78 & 4.09 & 5.04 & 4.32 & 4.11 \\
\hline $40-49$ & 3.28 & 3.81 & 3.14 & 2.95 & 3.51 & 2.6 & 3.31 & 3.05 & 3.3 \\
\hline $50-59$ & 2.41 & 2.99 & 2.27 & 1.98 & 2.68 & 1.6 & 2.02 & 2.11 & 2.76 \\
\hline $60-69$ & 1.85 & 2.34 & 1.73 & 1.42 & 2.12 & 1.15 & 1.38 & 1.53 & 2.43 \\
\hline $70-79$ & 1.37 & 1.59 & 1.31 & 1.11 & 1.53 & 1 & 1.09 & 1.15 & 1.95 \\
\hline $80-89$ & 1.46 & 1.51 & 1.44 & 1.38 & 1.51 & 1.36 & 1.37 & 1.39 & 1.73 \\
\hline \multicolumn{10}{|l|}{ Bihar } \\
\hline $0-9$ & 8.6 & 8.45 & 8.52 & 8.87 & 8.82 & 8.98 & 9.18 & 8.55 & 8.38 \\
\hline $10-19$ & 8.08 & 7.8 & 7.86 & 8.46 & 8.76 & 8.66 & 9.2 & 7.84 & 7.9 \\
\hline $20-29$ & 6.03 & 5.89 & 5.86 & 6.01 & 6.65 & 6.11 & 7.18 & 5.91 & 5.58 \\
\hline $30-39$ & 4.61 & 4.63 & 4.49 & 4.37 & 5.08 & 4.38 & 5.4 & 4.48 & 4.28 \\
\hline $40-49$ & 3.37 & 3.48 & 3.24 & 2.97 & 3.94 & 2.86 & 3.63 & 3.15 & 3.34 \\
\hline 50-59 & 2.44 & 2.59 & 2.3 & 1.98 & 3.04 & 1.79 & 2.25 & 2.18 & 2.66 \\
\hline $60-69$ & 1.79 & 1.93 & 1.67 & 1.38 & 2.3 & 1.25 & 1.5 & 1.55 & 2.18 \\
\hline $70-79$ & 1.19 & 1.24 & 1.14 & 0.99 & 1.42 & 0.95 & 1.02 & 1.05 & 1.52 \\
\hline $80-89$ & 1.27 & 1.28 & 1.26 & 1.23 & 1.32 & 1.22 & 1.23 & 1.24 & 1.39 \\
\hline \multicolumn{10}{|l|}{ Assam } \\
\hline $0-9$ & 8.25 & 8.03 & 8.19 & 8.84 & 8.1 & 8.89 & 8.86 & 8.41 & 7.66 \\
\hline $10-19$ & 8.25 & 8.05 & 8.15 & 8.81 & 8.25 & 9.02 & 9.35 & 8.14 & 7.69 \\
\hline $20-29$ & 6.72 & 6.77 & 6.65 & 6.46 & 7.01 & 7.19 & 8.26 & 6.43 & 6.2 \\
\hline $30-39$ & 5.34 & 5.74 & 5.39 & 4.5 & 5.79 & 5.31 & 6.69 & 4.84 & 4.99 \\
\hline $40-49$ & 4.14 & 4.82 & 4.26 & 2.97 & 4.72 & 3.54 & 4.69 & 3.52 & 4.08 \\
\hline 50-59 & 3.07 & 3.83 & 3.2 & 1.91 & 3.65 & 2.15 & 2.9 & 2.41 & 3.34 \\
\hline $60-69$ & 2.32 & 2.92 & 2.44 & 1.35 & 2.77 & 1.43 & 1.94 & 1.74 & 2.84 \\
\hline $70-79$ & 1.71 & 1.96 & 1.76 & 1.15 & 1.96 & 1.18 & 1.45 & 1.36 & 2.23 \\
\hline $80-89$ & 1.76 & 1.81 & 1.76 & 1.58 & 1.84 & 1.6 & 1.67 & 1.65 & 2.02 \\
\hline West Be & & & & & & & & & \\
\hline $0-9$ & 9.33 & 9.21 & 9.27 & 9.57 & 9.36 & 9.71 & 9.76 & 9.37 & 8.92 \\
\hline $10-19$ & 9.12 & 9.05 & 9.05 & 9.27 & 9.35 & 9.57 & 9.86 & 8.95 & 8.63 \\
\hline $20-29$ & 7.5 & 7.7 & 7.52 & 6.96 & 8.08 & 7.41 & 8.39 & 7.3 & 6.69 \\
\hline
\end{tabular}


Table 5 (continued)

\begin{tabular}{|c|c|c|c|c|c|c|c|c|c|}
\hline Age & Total & Seeing & Hearing & Speech & Movement & Mental Retardation & Mental Illness & Any other & Multiple \\
\hline $30-39$ & 5.99 & 6.48 & 6.11 & 5.15 & 6.62 & 5.47 & 6.67 & 5.54 & 5.33 \\
\hline $40-49$ & 4.66 & 5.32 & 4.79 & 3.69 & 5.35 & 3.81 & 4.84 & 4.1 & 4.34 \\
\hline $50-59$ & 3.39 & 4.01 & 3.51 & 2.43 & 4.01 & 2.44 & 3.15 & 2.79 & 3.47 \\
\hline $60-69$ & 2.46 & 2.91 & 2.57 & 1.73 & 2.88 & 1.7 & 2.11 & 1.94 & 2.84 \\
\hline $70-79$ & 1.81 & 2 & 1.88 & 1.44 & 1.97 & 1.42 & 1.6 & 1.53 & 2.2 \\
\hline $80-89$ & 1.94 & 1.97 & 1.96 & 1.84 & 1.98 & 1.84 & 1.88 & 1.86 & 2.11 \\
\hline \multicolumn{10}{|l|}{ Odisha } \\
\hline $0-9$ & 8.85 & 8.69 & 8.85 & 9.31 & 8.8 & 9.42 & 9.6 & 9.04 & 8.24 \\
\hline $10-19$ & 8.88 & 8.71 & 8.85 & 9.21 & 9.06 & 9.32 & 10.04 & 8.82 & 8.18 \\
\hline $20-29$ & 7.46 & 7.42 & 7.41 & 7.04 & 8.12 & 6.86 & 9.11 & 7.19 & 6.62 \\
\hline $30-39$ & 6.23 & 6.46 & 6.23 & 5.38 & 6.96 & 5.08 & 7.51 & 5.73 & 5.59 \\
\hline $40-49$ & 5.12 & 5.59 & 5.14 & 4 & 5.9 & 3.58 & 5.42 & 4.42 & 4.87 \\
\hline $50-59$ & 4.11 & 4.67 & 4.13 & 2.85 & 4.84 & 2.47 & 3.49 & 3.28 & 4.34 \\
\hline $60-69$ & 3.37 & 3.87 & 3.4 & 2.2 & 3.95 & 1.95 & 2.43 & 2.56 & 3.99 \\
\hline $70-79$ & 2.57 & 2.78 & 2.58 & 1.9 & 2.86 & 1.8 & 1.96 & 2.07 & 3.26 \\
\hline $80-89$ & 2.71 & 2.74 & 2.71 & 2.52 & 2.79 & 2.5 & 2.53 & 2.57 & 3.02 \\
\hline \multicolumn{10}{|c|}{ Madhya Pradesh } \\
\hline $0-9$ & 8.3 & 8 & 8.21 & 8.63 & 8.44 & 8.9 & 9 & 8.45 & 7.55 \\
\hline $10-19$ & 8.34 & 8.02 & 8.15 & 8.52 & 8.78 & 9 & 9.38 & 8.24 & 7.45 \\
\hline $20-29$ & 6.65 & 6.48 & 6.47 & 6.02 & 7.48 & 6.42 & 7.65 & 6.39 & 5.58 \\
\hline $30-39$ & 5.19 & 5.4 & 5.13 & 4.32 & 5.77 & 4.55 & 5.84 & 4.84 & 4.51 \\
\hline $40-49$ & 3.96 & 4.48 & 3.95 & 3.03 & 4.36 & 2.98 & 3.91 & 3.49 & 3.8 \\
\hline 50-59 & 2.98 & 3.65 & 2.97 & 2.07 & 3.31 & 1.82 & 2.31 & 2.39 & 3.26 \\
\hline $60-69$ & 2.33 & 2.98 & 2.34 & 1.53 & 2.58 & 1.28 & 1.53 & 1.72 & 2.92 \\
\hline $70-79$ & 1.69 & 2.04 & 1.71 & 1.21 & 1.8 & 1.09 & 1.18 & 1.29 & 2.32 \\
\hline $80-89$ & 1.72 & 1.8 & 1.72 & 1.57 & 1.74 & 1.54 & 1.56 & 1.59 & 2.02 \\
\hline \multicolumn{10}{|l|}{ Gujarat } \\
\hline $0-9$ & 9.23 & 9.05 & 8.95 & 9.44 & 9.5 & 9.65 & 9.71 & 9.22 & 8.78 \\
\hline $10-19$ & 9.15 & 8.94 & 8.85 & 9.25 & 9.74 & 9.51 & 9.96 & 8.85 & 8.51 \\
\hline $20-29$ & 7.49 & 7.39 & 7.41 & 6.9 & 8.62 & 6.37 & 8.66 & 7.1 & 6.16 \\
\hline $30-39$ & 5.94 & 6.11 & 6.11 & 5.13 & 6.8 & 4.45 & 7.07 & 5.49 & 4.78 \\
\hline $40-49$ & 4.53 & 5 & 4.94 & 3.75 & 4.89 & 3.01 & 5.06 & 4.07 & 3.82 \\
\hline 50-59 & 3.41 & 3.96 & 3.91 & 2.67 & 3.58 & 2.04 & 3.25 & 2.9 & 3.17 \\
\hline $60-69$ & 2.64 & 3.08 & 3.13 & 2.02 & 2.7 & 1.63 & 2.22 & 2.17 & 2.78 \\
\hline $70-79$ & 2.14 & 2.36 & 2.5 & 1.78 & 2.13 & 1.62 & 1.82 & 1.83 & 2.42 \\
\hline $80-89$ & 2.32 & 2.37 & 2.44 & 2.19 & 2.29 & 2.16 & 2.2 & 2.21 & 2.5 \\
\hline \multicolumn{10}{|c|}{ Maharashtra } \\
\hline $0-9$ & 9.67 & 9.48 & 9.55 & 9.97 & 9.78 & 9.98 & 10.12 & 9.54 & 9.33 \\
\hline $10-19$ & 9.31 & 9.07 & 9.18 & 9.78 & 9.7 & 9.51 & 10.16 & 8.86 & 8.81 \\
\hline $20-29$ & 7.71 & 7.47 & 7.63 & 8.17 & 8.63 & 6.33 & 9.21 & 7.23 & 6.59 \\
\hline $30-39$ & 6.11 & 6.04 & 6.12 & 6.41 & 7.07 & 4.22 & 7.66 & 5.6 & 5.08 \\
\hline $40-49$ & 4.68 & 4.86 & 4.79 & 4.71 & 5.46 & 2.88 & 5.57 & 4.17 & 4.07 \\
\hline $50-59$ & 3.51 & 3.83 & 3.67 & 3.28 & 4.17 & 2.04 & 3.62 & 3.03 & 3.32 \\
\hline $60-69$ & 2.73 & 3.08 & 2.92 & 2.36 & 3.18 & 1.69 & 2.47 & 2.31 & 2.85 \\
\hline $70-79$ & 2.13 & 2.34 & 2.29 & 1.87 & 2.29 & 1.64 & 1.91 & 1.88 & 2.39 \\
\hline $80-89$ & 2.25 & 2.3 & 2.31 & 2.18 & 2.28 & 2.13 & 2.18 & 2.18 & 2.39 \\
\hline \multicolumn{10}{|c|}{ Andhra Pradesh } \\
\hline $0-9$ & 9.42 & 9.07 & 9.33 & 9.76 & 9.53 & 9.84 & 9.96 & 9.45 & 9.12 \\
\hline 10-19 & 9.33 & 9.05 & 9.2 & 9.64 & 9.69 & 9.62 & 10.1 & 9.1 & 8.84 \\
\hline $20-29$ & 7.85 & 7.92 & 7.75 & 7.73 & 8.74 & 6.94 & 8.58 & 7.5 & 6.77 \\
\hline $30-39$ & 6.29 & 6.89 & 6.31 & 5.91 & 7 & 4.82 & 6.66 & 5.85 & 5.23 \\
\hline $40-49$ & 4.98 & 5.97 & 5.03 & 4.3 & 5.61 & 3.33 & 4.7 & 4.43 & 4.24 \\
\hline 50-59 & 3.92 & 5.06 & 3.97 & 3.04 & 4.44 & 2.37 & 3.16 & 3.31 & 3.58 \\
\hline $60-69$ & 3.16 & 4.2 & 3.22 & 2.33 & 3.47 & 1.93 & 2.36 & 2.58 & 3.17 \\
\hline $70-79$ & 2.39 & 2.88 & 2.45 & 1.97 & 2.47 & 1.84 & 1.96 & 2.08 & 2.62 \\
\hline $80-89$ & 2.67 & 2.78 & 2.7 & 2.55 & 2.67 & 2.53 & 2.55 & 2.58 & 2.79 \\
\hline \multicolumn{10}{|c|}{ Karnataka } \\
\hline $0-9$ & 8.93 & 8.64 & 8.86 & 9.18 & 9.13 & 9.28 & 9.39 & 8.96 & 8.59 \\
\hline 10-19 & 8.68 & 8.4 & 8.56 & 8.86 & 9.14 & 8.98 & 9.53 & 8.59 & 8.11 \\
\hline $20-29$ & 6.93 & 6.93 & 6.93 & 6.32 & 7.77 & 6.24 & 8.32 & 6.88 & 5.72 \\
\hline $30-39$ & 5.16 & 5.47 & 5.18 & 4.36 & 5.77 & 4.11 & 6.63 & 5.13 & 4.16 \\
\hline $40-49$ & 3.78 & 4.3 & 3.8 & 2.96 & 4.23 & 2.63 & 4.67 & 3.64 & 3.14 \\
\hline 50-59 & 2.71 & 3.35 & 2.72 & 1.94 & 3.03 & 1.63 & 2.84 & 2.46 & 2.4 \\
\hline $60-69$ & 1.98 & 2.61 & 1.99 & 1.36 & 2.12 & 1.15 & 1.72 & 1.7 & 1.95 \\
\hline $70-79$ & 1.38 & 1.75 & 1.41 & 1.04 & 1.38 & 0.96 & 1.13 & 1.19 & 1.52 \\
\hline $80-89$ & 1.35 & 1.46 & 1.37 & 1.25 & 1.33 & 1.23 & 1.27 & 1.29 & 1.45 \\
\hline Kerala & & & & & & & & & \\
\hline $0-9$ & 10.13 & 9.77 & 9.73 & 10.43 & 10.22 & 10.81 & 10.71 & 10.17 & 9.85 \\
\hline $10-19$ & 9.97 & 9.71 & 9.49 & 10.08 & 10.18 & 10.6 & 10.83 & 9.79 & 9.58 \\
\hline $20-29$ & 8.99 & 8.94 & 8.48 & 8.49 & 9.68 & 8.31 & 10.64 & 8.67 & 8.26 \\
\hline $30-39$ & 7.91 & 8.43 & 7.52 & 7 & 8.85 & 6.04 & 9.77 & 7.44 & 6.95 \\
\hline $40-49$ & 6.63 & 7.8 & 6.5 & 5.48 & 7.5 & 4.11 & 7.85 & 6.2 & 5.67 \\
\hline 50-59 & 5.22 & 6.69 & 5.37 & 4.03 & 5.91 & 2.77 & 5.37 & 4.81 & 4.55 \\
\hline $60-69$ & 4 & 5.35 & 4.38 & 3 & 4.35 & 2.17 & 3.49 & 3.59 & 3.78 \\
\hline $70-79$ & 3.1 & 3.91 & 3.57 & 2.42 & 3.14 & 2.06 & 2.56 & 2.76 & 3.23 \\
\hline
\end{tabular}

(continued on next page) 
Table 5 (continued)

\begin{tabular}{|c|c|c|c|c|c|c|c|c|c|}
\hline Age & Total & Seeing & Hearing & Speech & Movement & Mental Retardation & Mental Illness & Any other & Multiple \\
\hline $80-89$ & 2.92 & 3.16 & 3.19 & 2.64 & 2.89 & 2.56 & 2.67 & 2.76 & 3.1 \\
\hline \multicolumn{10}{|c|}{ Tamil Nadu } \\
\hline $0-9$ & 9.61 & 9.35 & 9.42 & 9.81 & 9.75 & 9.81 & 10 & 9.59 & 9.5 \\
\hline 10-19 & 9.39 & 9.21 & 9.17 & 9.54 & 9.77 & 9.35 & 10.15 & 9.23 & 9.06 \\
\hline $20-29$ & 7.97 & 8 & 7.83 & 7.56 & 8.95 & 6.55 & 9.66 & 7.81 & 6.88 \\
\hline $30-39$ & 6.23 & 6.75 & 6.38 & 5.55 & 7.06 & 4.34 & 8.26 & 6.03 & 5.04 \\
\hline $40-49$ & 4.64 & 5.48 & 5.02 & 3.92 & 5.18 & 2.81 & 5.88 & 4.4 & 3.67 \\
\hline $50-59$ & 3.34 & 4.22 & 3.73 & 2.63 & 3.76 & 1.85 & 3.5 & 3.09 & 2.68 \\
\hline $60-69$ & 2.43 & 3.17 & 2.76 & 1.9 & 2.66 & 1.46 & 2.2 & 2.2 & 2.09 \\
\hline $70-79$ & 1.84 & 2.25 & 2.05 & 1.56 & 1.88 & 1.42 & 1.68 & 1.7 & 1.74 \\
\hline 80-89 & 2.03 & 2.15 & 2.1 & 1.95 & 2.03 & 1.92 & 1.98 & 1.98 & 2.04 \\
\hline
\end{tabular}

\section{Proportion of Life Spent Disability-free Gender-wise}

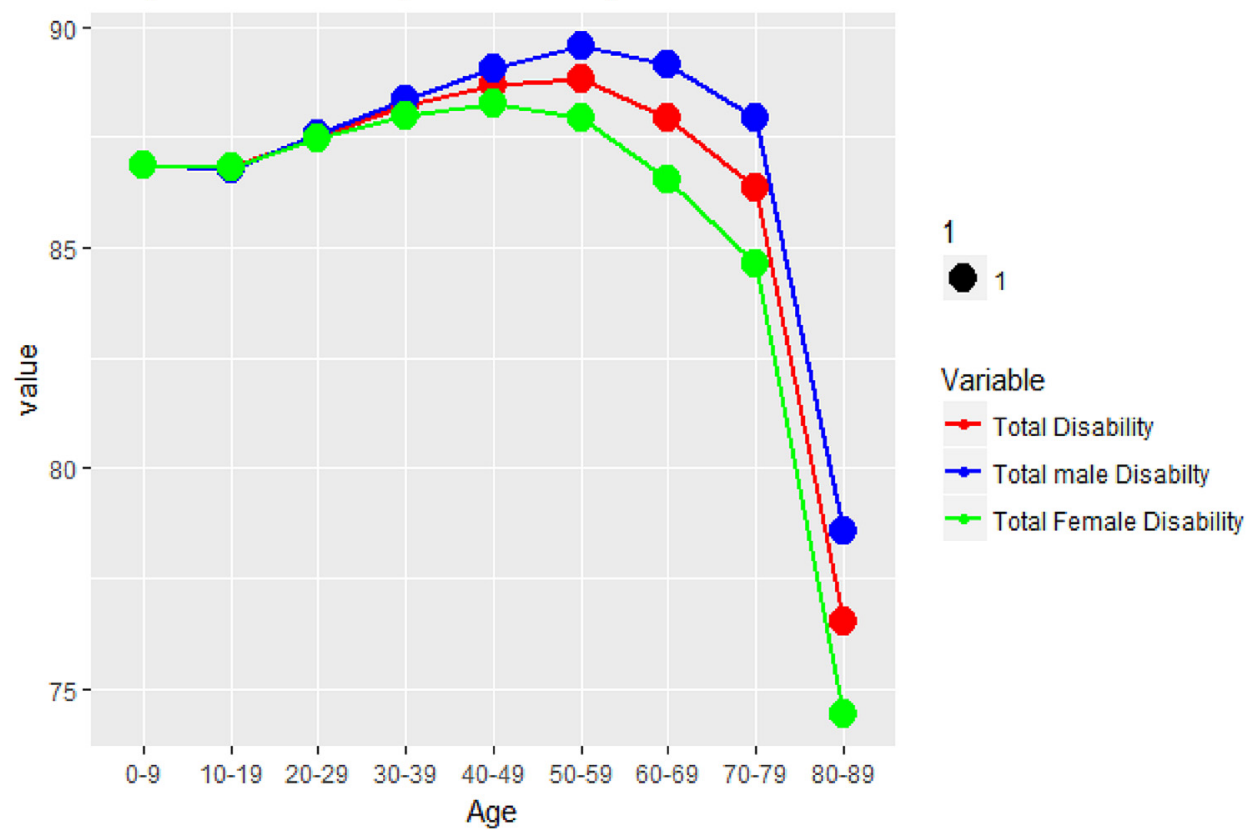

Fig. 4. Proportion of disability-free life expectancy by gender and age group in India.

\section{Proportion of life spent Disability-free by all types of Disability}

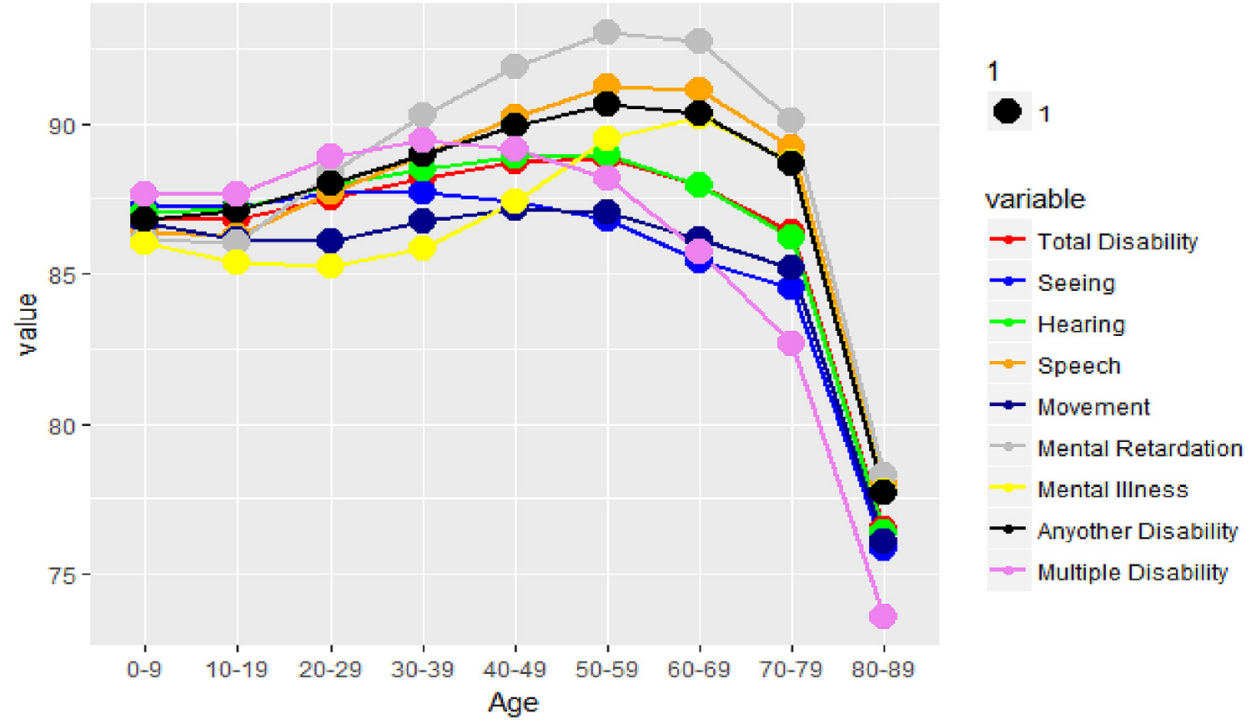

Fig. 5. Proportion of life spent disability-free by type of disability in India. 
disability-free life expectancy and lowest among speech disability, whereas, in case of females it was longer for multiple disabilities and shorter for mental retardation. Life lived with a disability is highest for mental illness and mental retardation throughout the country. In most of the states of the southern region, a life lived with a disability is shorter for persons suffering from seeing disability, whereas in other regions of the country it is lowest for multiple disabilities.

\section{Author contributions}

RSM \& RM conceived the idea and designed the experiment. RSM and $\mathrm{RM}$ analysed the data, interpreted the results, and drafted the manuscript. SKM helped a lot in last phase and finalised the manuscript. All authors reviewed the manuscript and approved the final manuscript for submission for publication.

\section{References}

1. Census of India. Data on Disability. New Delhi: Office of the Registrar General \& Census Commissioner; 2011 15-10-2017. Available at http://www.disabilityaffairs. gov.in/upload/uploadfiles/files/disabilityinindia2011data.pdf.

2. Mathers CD, Lopez AD, Murray CJ. The burden of disease and mortality by condition: data, methods and results for 2001. Global Burden of Disease and Risk Factors. 2006; 2006:88.

3. Myers GC, Lamb VL, Agree EM. Patterns of disability change associated with the epidemiologic transition. Determining Health Expectancies. 2003; 2003:59-74.

4. WHO. Disabilities. Accessed on 16-04-2018 http://www.who.int/topics/disabilities/ en/; 2018.

5. Myers GC, Lamb VL. Theoretical Perspectives on Healthy Life Expectancy. COLLOQUESINSTITUT NATIONAL DE LA SANTE ET DE LA RECHERCHE MEDICALE COLLOQUES ET SEMINAIRES; 1993 109-109.

6. WHO and World Bank. World Report on Disability 2011; 2011 http://www.who.int/ disabilities/world_report/2011/en/ Accessed on 16-04-18.

7. Tomlinson M, Swartz L, Officer A, Chan KY, Rudan I, Saxena S. Research priorities for health of people with disabilities: an expert opinion exercise. Lancet. 2009;374(9704):1857-1862.

8. Hosseinpoor AR, Williams JS, Jann B, et al. Social determinants of sex differences in disability among older adults: a multi-country decomposition analysis using the World Health Survey. Int J Equity Health. 2012;11(1):52.

9. RGI. Office of the registrar general. Available on http://www.censusindia.gov.in/ vital_statistics/.html; 2013.

10. Minicuci N. Influence of level of education on disability-free life expectancy by sex: the ILSA study. Exp Gerontol. 2005;40(12):997-1003.

11. Murray CJ, Lopez AD. Regional patterns of disability-free life expectancy and dis ability-adjusted life expectancy: global Burden of Disease Study. Lancet. 1997;349(9062):1347-1352.

12. Thomas MB, James KS, Sulaja S. Does living longer mean living healthier? Exploring disability-free life expectancy in India. Indian J Gerontol. 2014;28(3).

13. Gutiérrez-Fisac JL, Gispert R, Solà J. Factors explaining the geographical differences in disability-free life expectancy in Spain. J Epidemiol Community Health. 2000;54(6):451-455.

14. Jagger C. Health Expectancy Calculation by the Sullivan Method: A Practical Guide. 1999; 1999.

15. Mathers C. Health Expectancies in Australia 1981 and 1988. Australian Government Pub. Service; 1991

16. Fries JF. The compression of morbidity". Milbank memorial fund. Q. Health Soc 1983;61:397-419.

17. Fries j. Aging, natural death and the compression of morbidity-reply. $N$ Engl J Med. $1980 ; 303(23) 1370-1370$

18. Fries JF. Aging, natural death, and the compression of morbidity. $N$ Engl J Med. 1980;303:130-135.

19. Robine JM, Ritchie K. Healthy life expectancy: evaluation of global indicator of change in population health. BMJ. 1991;302(6774):457-460.

20. Crimmins EM, Hayward MD, Hagedorn A, Saito Y, Brouard N. Change in disabilityfree life expectancy for Americans 70-years-old and older. Demography. 2009;46(3):627-646.

21. Jagger C, Weston C, Cambois E, et al. Inequalities in health expectancies at older ages in the European union: findings from the survey of health and retirement in Europe (SHARE). J Epidemiol Community Health. 2011;65:1030-1035. 